\title{
FAKTOR-FAKTOR YANG MEMPENGARUHI TERHADAP BERKURANGNYA UMUR RENCANA KONSTRUKSI JALAN HOTMIX DI KABUPATEN TULUNGAGUNG
}

(Studi kasus : Ruas Jalan Hotmix di Kabupaten Tulungagung Jawa Timur)

Guminto $^{1}$, Nusa Sebayang ${ }^{2}$, Maranatha, W. ${ }^{3}$

1Degree Program of Civil Engineering Department, National Institut of Technology, Malang, Indonesia-65140

2,3Post Graduate Program of Civil Engineering Department, National Institut of Technology, Malang, Indonesia-65140

\begin{abstract}
ABSTRAK
Ketersediaan Jalan dalam pemenuhan terhadap pencapaian peningkatan perekonomian sebagai bagian sistem transportasi nasional yang mempunyai peranan penting terutama dalam mendukung ekonomi, sosial budaya, lingkungan, politik, serta pertahanan dan keamanan. Dari aspek ekonomi, jalan sebagai modal sosial masyarakat merupakan penghubung di antara proses produksi, pasar dan konsumen akhir yang sampai ke masyarakat. Kwalitas sarana prasaran terpengaruhi oleh owner, konsultan dan kontraktor pada waktu proses pengerjaan. Perjalanan pelaksanaan sangat terpengaruh dengan banyak faktor dilapangan

Berdasarkan uji $F$ secara simultan didapat $F_{\text {hitung }}$ lebih besar dari $F_{\text {tabel, }}$ sehingga seluruh variabel bebas berpengaruh terhadap tidak tercapainya umur rencana jalan hotmix, sedangkan secara parsial (uji $t$ ) variabel yang berpengaruh ialah variabel kendaraan $\left(X_{2}\right)$, variabel lingkungan $\left(X_{3}\right)$ dan variabel kondisi tanah $\left(X_{7}\right)$ karena nilai $t$ hitung $>\mathrm{t}$ tabel. Faktor yang paling dominan dalam mempengaruhi tidak tercapainya umur rencana jalan hotmix yaitu variabel kendaraan dengan nilai coofisien beta (Koefisien beta adalah nilai prediksi sebuah variabel di dalam model terhadap variabel response) yang paling besar yaitu 0,514 atau $51,40 \%$ nilai signifikan 0,013 untuk indikatornya ialah jumlah kendaraan dengan melihat nilai looding faktor tertinggi sebesar 0,627 dan nilai keragamannya $62,70 \%$.

Pola dan Strategi yang digunakan untuk mengatasi tidak tercapainya umur rencana jalan hotmix di Kabupaten Tulungagung adalah dengan menyediakan jembatan timbang untuk mengidentifikasi dan mengetahui tonase kendaraan yang melaului ruas jalan dan memberlakukan kecepatan minimal dan jam tertentu khususnya untuk kendaraan berat; Memperhitungkan dengan cermat dalam menentukan titik tertentu, dan melakukan analisis peta kontur medan; Melakukan test sandcon agar mengetahui gaya geser tanah dan daya dukung tanah yang standard nasional (AISC). Pemeliharaan secara berkala menjadi bagian terpenting dalam umur rencana jalan.

Kata Kunci : Faktor, Umur Rencana, Variabel, Strategi
\end{abstract}

\section{PENDAHULUAN}

Ketersediaan Jalan dalam pemenuhan terhadap pencapaian peningkatan perekonomian sebagai bagian sistem transportasi nasional yang mempunyai peranan penting terutama dalam mendukung ekonomi, sosial budaya, lingkungan, politik, serta pertahanan dan keamanan. Dari aspek ekonomi, jalan sebagai modal sosial masyarakat merupakan penghubung di antara proses produksi, pasar dan konsumen akhir yang sampai ke masyarakat.

Lalu Lintas dan Angkutan Jalan mempunyai peran strategis dalam mendukung pembangunan dan integrasi nasional sebagai bagian dari upaya memajukan kesejahteraan umum sebagaimana diamanatkan oleh Undang-Undang Dasar Negara Republik Indonesia Tahun 1945. Sebagai bagian dari sistem transportasi nasional, Lalu Lintas dan Angkutan Jalan harus dikembangkan potensi dan perannya untuk mewujudkan keamanan, kesejahteraan, ketertiban berlalu lintas dan Angkutan Jalan dalam rangka mendukung pembangunan ekonomi dan pengembangan ilmu pengetahuan dan teknologi, otonomi daerah, serta akuntabilitas penyelenggaraan negara. asas dan tujuan untuk menciptakan Lalu Lintas dan Angkutan Jalan yang aman, selamat, tertib, lancar, dan terpadu dengan moda angkutan lain, juga mempunyai tujuan untuk mendorong perekonomian nasional, mewujudkan kesejahteraan rakyat, persatuan dan kesatuan bangsa, serta mampu menjunjung tinggi martabat bangsa. (Undang-undang Nomor 32, tahun 2009)

Tujuan utama pembuatan struktur konstruksi jalan kabupaten di Kabupaten Tulungagung adalah untuk mengurangi tegangan atau tekanan akibat beban roda kendaraan, sehingga mencapai tingkat nilai yang dapat diterima oleh tanah yang menyokong struktur jalan tersebut, kendaraan pada posisi diam atau berhenti di atas struktur yang diperkeras menimbulkan beban langsung (tegangan statis) pada perkerasan yang terkonsentrasi pada bidang kontak yang kecil antara roda dan perkerasan. Ketika kendaraan bergerak berjalan, timbul tambahan tegangan dinamis akibat pergerakan kendaraan ke atas dan ke bawah karena ketidakrataan perkerasan, beban angin dan sebagainya (Wignall Arthur, 2003) 
Guminto, Nusa Sebayang, Maranatha W

Kendaraan yang mengkibatkan tegangan dinamis, hal ini akan menimbulkan efek "pukulan" tambahan pada permukaan jalan ketika kendaraan bergerak atau berjalan. Perkerasan lentur jalan raya telah dirancang untuk bertahan sampai 20 tahun dan Umur rencana overlay perkerasan lentur adalah 10 tahun. (PUPR. SE: 04//SE/Db/2017. Manual Desain Perkerasan Jalan Revisi 2017,). Sebuah perkerasan jalan berkualitas apabila "dapat mencapai umur rencana" sesuai desain perencanaan dengan dilewati sejumlah kendaraan yang direncanakan, apabila pelaksanaan konstruksi perkerasan jalan tersebut dilakukan dengan baik, dan semua material sesuai dengan standar yang diminta dalam spesifikasi desain serta selalu digunakan dengan benar (Wignall Arthur, 2003).

Untuk mencapai umur rencana jalan diperlukan manajemen pengelolaan proyek untuk mengidentifikasi/kuantifikasi, menganalisis, menanggapi dan akhirnya mengendalikan. Salah satu pendekatan yang digunakan dalam melakukan identifikasi adalah dengan cause and effect, yaitu dengan menganalisis apa yang akan terjadi dan potensi akibat yang akan ditimbulkan (Soeharto, 2001).

Konstruksi jalan raya adalah merupakan suatu konstruksi yang dibuat sedemikian rupa sehingga dapat memikul beban lalu lintas (kendaraan) yang melintas diatasnya tanpa mengalami perubahan struktur pada permukaan jalan tersebut. Dengan berkembangnya angkutan darat, terutama kendaraan bermotor yang meliputi jenis ukuran dan jumlah maka masalah kelancaran arus lalu lintas, keamanan, kenyamanan dan daya dukung dari perkerasan jalan harus menjadi perhatian (Alamsyah, 2006)

Dalam pelaksanaan proyek perkerasan lentur jalan kabupaten di Kabupaten Tulungagung, ada beberapa faktor yang diduga berpengaruh terhadap tidak tercapainya umur rencana jalan, seperti : Perubahan Desain, kendaraan, Lingkungan, Sumber Daya Manusia, Pelaksanaan Pekerjaan, Peralatan, Kondisi Tanah, Material dan Keuangan.

Pihak-pihak terkait seperti Owner, Kontraktor dan Konsultan Pengawas harus dapat mengidentifikasi faktor-faktor yang berdampak pada tidak tercapainya umur rencana jalan dan bagaimana menangani faktorfaktor yang ada, sehingga kualitas konstruksi jalan dapat bertahan selama umur/masa pelayanan jalan serta pembangunan dapat berkelanjutan sesuai dengan program pembangunan nasional.

Berdasarkan kondisi Pembangunan Jalan Kabupaten Tulungagung, Dinas PU Bina Marga dan Cipta Karya Kabupaten Tulungagung melakukan perbaikan dan peningkatan jalan pada ruas - ruas jalan yang tidak sesuai umur rencana yang sudah ditetapkan. Harapan penelitian dari penelitian dapat memberikan manfaat untuk peningkatan kwalitas pekerjaan dan mengetahui Faktor-faktor Yang Mempengaruhi Terhadap Berkurangnya Umur Rencana Kontruksi Jalan Hotmix di Kabupaten Tulungagung.

\section{LANDASAN TEORI}

\section{Managemen Kontruksi}

Dalam suatu kegiatan konstruksi diperlukan suatu manajemen atau pengelolaan yang dituntut memiliki kinerja, kecermatan, ketelitian, kecepatan, keamanan, dan keselamatan kerja yang tinggi untuk dapat memperoleh hasil yang efektif dan efisien. Rangkaian kegiatan kerja dalam suatu proyek konstruksi sering juga disebut dengan istilah POAC (Planning, Organizing, Actuating, Controlling). Artinya adalah kegiatan proyek harus direncanakan secara matang mulai dari bagaimana prosesnya, dan sampai kapan proyek tersebut akan selesai, organisasi dengan setiap orang yang terkait baik dengan mandor, pekerja maupun tukang. Agar komunikasi dan koordinasi dapat berjalan dengan baik, proses pelaksanaan proyek haruslah tepat, teliti, cermat, dan cepat. Suatu proyek harus dikelola dengan baik, tepat, dan secara profesional dan agar hasil dari proyek tersebut maksimal (Sutanto Hidayat dan Maranatha W, 2019)

\section{Jalan}

Undang-undang nomor 38 tahun 2004 pasal 1 tentang jalan bahwa jalan adalah prasarana transportasi darat yang meliputi segala bagian jalan, termasuk bangunan pelengkap dan perlengkapannya yang diperuntukan bagi lalu lintas, yang berada pada permukaan tanah, di atas permukaan tanah, di bawah permukaan tanah, dan atau air serta di atas permukaan air, kecuali jalan kereta api, jalan lori dan jalan kabel

Perkerasan Lentur (Flexible Pavement) yaitu satu jenis konstruksi perkerasan jalan yang menggunakan bahan agregat dan aspal sebagai material pengikatnya, sehingga mempunyai sifat lentur yang baik, biasanya dipakai untuk perkerasan HRS (Hot Rolled Sheet), Aspal Buton, SMA (Split Mastic Asphalt) dan Lapis Penetrasi

Campuran aspal panas (Hot Mix) adalah jenis campuran yang dibuat untuk melakukan pekerjaan pengaspalan jalan yang ditempatkan sebagai lapis konstruksi paling atas (Surface Course) yang menerima beban secara langsung dengan roda kendaraan yang melewati diatasnya. Adapun komposisi campuran hot mix terdiri dari : agregat kasar, agregat halus, aspal dan abu batu (filler), sedangkan suhu campuran aspal panas yang dijinkan adalah antara $145^{\circ} \mathrm{C}-155^{\circ} \mathrm{C}$, sedangkan suhu yang diijinkan untuk penghamparan $>97^{\circ} \mathrm{C}-145^{\circ} \mathrm{C}$.

\section{Konstruksi Lapisan Perkerasan}

Lapisan Permukaan (Surfase Course) adalah bagian yang terletak paling atas dari suatu konstruksi perkerasan jalan yang mendapat pembebanan paling besar dari beban-beban lalu lintas yang lewat diatasnya. Lapis Pondasi Atas (Base Course) adalah lapisan perkerasan yang terletak diantara lapis pondasi bawah dan lapis 
Faktor-faktor Yang Mempengaruhi Terhadap Berkurangnya Umur Rencana Kontruksi Jalan Hotmix di Kabupaten Tulungagung.

Guminto, Nusa Sebayang, Maranatha W

permukaan. Lapis Pondasi Bawah (Sub Bas Course) adalah lapis perkerasan yang terletak antara lapis pondasi atas dan tanah dasar. Lapisan Tanah Dasar (Sub-Grade) adalah Lapis tanah dasar dapat berupa tanah asli yang dipadatkan jika tanah aslinya baik, tanah yang didatangkan dari tempat lain dan dipadatkan atau tanah yang distabilkan dengan kapur atau bahan lainnya, Lapisan tanah setebal $50-100 \mathrm{~m}$ akan diletakaan lapis pondasi bawah dinamakan tanah dasar.

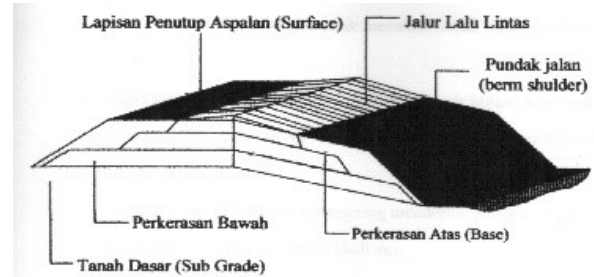

Keempat Lapisan perkerasan tersebut berfungsi untuk menerima dan menyebarkan beban lalu lintas tanpa menimbulkan kerusakan yang berarti pada konstruksi jalan itu sendiri dengan demikian memberikan kenyamanan kepada pengemudi kendaraan selama palayanan jalan. Untuk itu dalam perencanaan perlu dipertimbangkan seluruh faktor-faktor yang dapat mempengaruhi fungsi pelayanan konstruksi jalan seperti (Alamsyah, 2006). Penerimaan Sifat gaya-gaya jalan makin ke bawah makin menyebar, maka pengaruhnya makin ke bawah makin berkurang, sehingga muatan yang diterima oleh bagian konstruksi tersebut juga berbeda-beda berdasakan :

1. Fungsi Jalan

2. Kinerja Perkerasan Jalan

3. Kinerja Perkerasan Jalan

4. Sifat Tanah Dasar

5. Kondisi Lingkungan

\section{Campuran Aspal Panas (Hot Mix)}

Campuran aspal panas (Hot Mix) adalah jenis campuran yang dibuat untuk melakukan pekerjaan pengaspalan jalan yang ditempatkan sebagai lapis konstruksi paling atas (Surface Course) yang menerima beban secara langsung dengan roda kendaraan yang melewati diatasnya. Adapun komposisi campuran hot mix terdiri dari : agregat kasar, agregat halus, aspal dan abu batu (filler), sedangkan suhu campuran aspal panas yang diijinkan adalah antara $145^{\circ} \mathrm{C}-155^{\circ} \mathrm{C}$, sedangkan suhu yang diijinkan untuk penghamparan $>97^{\circ} \mathrm{C}-145^{\circ} \mathrm{C}$.

Karakteristik campuran yang harus dimiliki oleh campuran aspal panas (Hot Mix) adalah stabilitas, Durabilitas (Keawetan/Daya Tahan), fleksibilias (Kelenturan), skid Resistance (Tahan Geser/Kekerasan), ketahanan Kelelahan (Fatique Resistance), workability (Kemudahan Pelaksanaan),

Tabel 1

\begin{tabular}{|c|c|c|c|c|c|c|}
\hline \multirow{4}{*}{ Jenis Pemeriksaan } & syaratan Asp & \multirow{2}{*}{\multicolumn{4}{|c|}{ Persyaratan }} & \multirow{4}{*}{ Satuan } \\
\hline & Cara & & & & & \\
\hline & \multirow{2}{*}{$\begin{array}{l}\text { Pemeriksaan } \\
\text { (MPBJ) }\end{array}$} & \multicolumn{2}{|c|}{ Pen. 60} & \multicolumn{2}{|c|}{ Pen. 80} & \\
\hline & & Min. & Mak. & \multirow{2}{*}{ Min. } & Mak. & \\
\hline 1. Penetrasi $\left(25^{\circ} \mathrm{C} 5\right.$ detik) & & & & & & \\
\hline 2. Titik Lembek (Ring Bell) & PA.0301-76 & 60 & 79 & 80 & 99 & $0.1 \mathrm{~mm}$ \\
\hline 3. Titik Nyala (Clev. Open Cup) & PA. 0302-76 & 48 & 55 & 46 & 54 & ${ }^{\circ} \mathrm{C}$ \\
\hline 4. Kehilangan Berat $\left(163^{\circ}, 5 \mathrm{jam}\right)$ & PA. 0303-76 & 200 & - & 225 & - & ${ }^{\circ} \mathrm{C}$ \\
\hline 5. Kelihatan $\left(\mathrm{C}_{2} \mathrm{HCL}_{3}\right)$ & PA.0304-76 & - & 0.8 & - & 0.1 & $\%$ Berat \\
\hline 6. Daktilasi $\left(25^{\circ} \mathrm{C}, \mathrm{cm} /\right.$ menit $)$ & PA. 0305-76 & 99 & - & 99 & - & $\%$ Berat \\
\hline 7. Penetrasi stl kehilangan Berat**) & PA.0306-76 & 100 & - & 100 & - & $\mathrm{Cm}$ \\
\hline 8. Daktilitas stl kehilangan berat*) & PA.0301-76 & 50 & - & 50 & - & $\%$ Semla \\
\hline \multirow[t]{2}{*}{ 9. Berat Jenis $25^{\circ} \mathrm{C}$} & PA.0306-76 & 75 & - & 75 & - & $\mathrm{Cm}$ \\
\hline & PA.0307-76 & 1 & - & 1 & - & $\mathrm{Gr} / \mathrm{cc}$ \\
\hline
\end{tabular}

Sumber: Berdasarkan Thin Film Oven Test (AASHTO T - 179) (DPU, 1987)

\section{Faktor-faktor Yang Diduga Berpengaruh Terhadap Tidak Tercapainya Umur Rencana Jalan.}

Kontruksi jalan memiliki umur rencana (UR) yang pada awalnya menjadi dasar perencanaan, pada umur pakai mengalami beberapa Faktor-Faktor Yang mempengaruhi tidak tercapainya umur rencana jalan dipengaruhi :

1. Perubahan Desain

2. Kendaraan

3. Lingkungan Kerja

4. Sumber Daya Manusia

5. Pelaksanaan Pekerjaan

6. Peralatan 
Faktor-faktor Yang Mempengaruhi Terhadap Berkurangnya Umur Rencana Kontruksi Jalan Hotmix

di Kabupaten Tulungagung.

Guminto, Nusa Sebayang, Maranatha W

7. Kondisi Tanah

8. Material

9. Keuangan

\section{METODE PENELITIAN}

Penelitian dilakukan dengan metode analisis deskriptif, yaitu mengetahui faktor-faktor yang berpengaruh terhadap tidak tercapainya umur rencana jalan kabupaten di Kabupaten Tulungagung dan mendapat faktor faktor yang paling dominan mempengaruhinya serta menentukan strategi. Pengumpulan data dengan menggunakan pengamatan dan metode angket atau kuesioner sebagai alat pengumpulan data. Penelitian ini menggunakan metode survey dengan cara menjaring pendapat, pengalaman dan sikap responden melalui kuesioner.

\section{Pengumpulan Data}

Data yang didapat dari populasi yang berkecimpung dalam perencanaan dan pelaksanaan jalan hotmix baik ke owner, konsultan, kontraktor yang relevan dengan pekerjaan jalan hotmix di Kabupaten Tulungagung. Pengumpulan data dilakukan dengan kuisioner ke pelaku proyek dengan tujuan agar tidak terjadi kesalahan dalam memahami pernyataan dan para responden dapat memberi data yang sesuai dan akurat

\section{Variabel Penelitian}

variabel penelitian adalah sesuatu hal berbentuk apa saja yang ditetapkan oleh peneliti untuk dipelajari sehingga diperoleh informasi tentang hal tersebut kemudian ditarik kesimpulannya (Sugiyono, 2009). Variabel penelitian meliputi :

1. Variabel independen atau variabel bebas $(X)$ yang menjadi sebab berubahnya variabel dependen. Variabel independen yang digunakan dalam penelitian ini adalah:

- Perubahan Desain $\left(X_{1}\right)$.

- Kendaraan $\left(X_{2}\right)$

- $\quad$ Lingkungan $\left(X_{3}\right)$

- Sumber Daya Manusia $\left(X_{4}\right)$

- Pelaksanaan Pekerjaan $\left(X_{5}\right)$

- Peralatan $\left(\mathrm{X}_{6}\right)$

- Kondisi Tanah $\left(\mathrm{X}_{7}\right)$

- Material $\left(X_{8}\right)$

- $\quad$ Keuangan $\left(X_{9}\right)$

2. Variabel dependen atau variabel terikat $(Y)$, merupakan variabel yang dipengaruhi oleh variabel bebas. Dalam penelitian ini, yang digunakan sebagai variabel dependen adalah

- $\quad$ Tidak Tercapainya Umur Rencana Jalan (Y) Variabel Y adalah Ruas jalan kabupaten di Kabupaten Tulungagung banyak yang mengalami kerusakan dini, sehingga Tidak tercapainya umur rencana jalan seperti yang direncanakan.

\section{Skala pengukuran variabel}

Skala pengukuran variabel yang digunakan dalam penelitian adalah skala likert. Skala likert merupakan skala pengukuran yang menunjukkan tingkat persetujuan terhadap suatu pernyataan. Dalam skala likert tingkat persetujuan diukur melalui dari 5 pilihan jawaban yang terdiri dari :

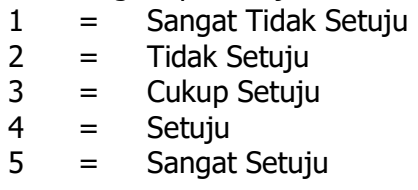

\section{Populasi}

Kumpulan seluruh individu dengan kualitas yang telah ditetapkan, kualitas atau ciri tersebut dinamakan variabel. Populasi ditentukan berdasarkan pengalaman dilapangan dari orang-orang yang dianggap berpengalaman dan mengetahui tentang proses pembangunan dari aspek perencanaan awal, proses pelelangan dan proses pembangunan fisik dilapangan

\section{Sampel}

kumpulan dari unit sampling yang ditarik dan merupakan sub dari populasi. Sedangkan sampel diambil dari populasi yang dianggap mewakili semua instansi/perusahaan tersebut (Sugiyono, 2009)

\section{Uji validitas dan reliabilitas}

1. Validitas adalah suatu ukuran yang menunjukan tingkatan-tingkatan atau kesahihan, instrument dikatakan valid apabila mampu mengukur yang diinginkan dan mengungkapkan data dari variabel yang diteliti secara tepat Validitas diukur dengan mengkorelasi antar skor masing-masing variabel dengan skor total yang merupakan skor butir. Validitas instrumen diperoleh dari hasil korelasi antar skor instrumen, dikorelasikan 
Faktor-faktor Yang Mempengaruhi Terhadap Berkurangnya Umur Rencana Kontruksi Jalan Hotmix

di Kabupaten Tulungagung.

Guminto, Nusa Sebayang, Maranatha W

dengan skor total, kemudian dibandingkan dengan nilai kritis "r". Jika korelasi setiap instrumen pertanyaan lebih besar arti nilai butir "r" maka instrumen tersebut dapat dinyatakan valid, kaidah keputusan validitas adalah Jika $\mathrm{t}_{\text {hitung }}>t_{\text {tabe/ }}$ berarti valid dan jika $\mathrm{t}_{\text {hitung }}<\mathrm{t}_{\text {tabel }}$ berarti tidak valid.

$$
r=\frac{n \cdot(\Sigma X Y)-\Sigma X \cdot \Sigma Y}{\sqrt{ }\left[\left\{n \cdot \Sigma X^{2}-(\Sigma X)^{2}\right\} \cdot\left\{n \cdot \Sigma Y^{2}-(\Sigma Y)^{2}\right\}\right]}
$$

2. Reliabilitas adalah sesuatu instrumen yang cukup dapat dipercaya untuk digunakan sebagai pengumpul data karena instrumen tersebut sudah baik. Alat ukur yang baik tidak akan bersifat tendensius atau mengarahkan responden untuk memilih jawaban-jawaban tertentu. Instrumen yang sudah dapat dipercaya juga, adapun teknik pengujian Reliabilitas yaitu dengan menggunakan nilai koefisien yang nilainya berkisar mulai dari angka 0 sampai dengan angka 1 . Semakin mendekati angka 1 semakin realibel ukuran yang dipakai, untuk menunjukan bahwa semakin reliabel bilamana nilai Cronbach alpha di atas 0,6 dan dibawah 0,6 menunjukan total reliabel, kaidah keputusan reliabel adalah Jika $r_{h i t u n g}>t_{t a b e l}$ berarti reliabel dan jika $\mathrm{t}_{\text {hitung }}<\mathrm{t}_{\text {tabe/ }}$ berarti tidak reliabel.

- Masukkan angka-angka statistik dengan rumus varians total dan varians item :

$$
\begin{aligned}
& \mathrm{s}_{1}^{2}=\frac{\Sigma \mathrm{X}_{1}}{\mathrm{n}}-\frac{\left(\Sigma \mathrm{X}_{1}\right)^{2}}{\mathrm{n}^{2}} \mathrm{dan} \\
& \mathrm{s}_{1}^{2}=\frac{\mathrm{JK}_{1} 2}{\mathrm{n}}-\frac{\mathrm{JK}_{\mathrm{s}}}{\mathrm{n}^{2}} \\
& \text { dimana : } \\
& \sum \mathrm{X}_{1}=\text { jumlah skor responden } \quad S_{t}^{2} \quad=\text { varian total } \\
& \mathrm{JK}_{1}=\text { jumlah kuadrat seluruh skor item } \\
& \mathrm{JK}_{\mathrm{s}} \quad=\text { jumlah kuadrat subyek } \\
& \mathrm{n} \quad=\text { jumlah responden } \\
& S_{i}^{2} \quad=\text { varian tiap item }
\end{aligned}
$$

- Setelah hasil perhitungan didapat, kemudian dimasukkan kedalam rumus Alpha Cronbach (Sugiyono, 2009) :

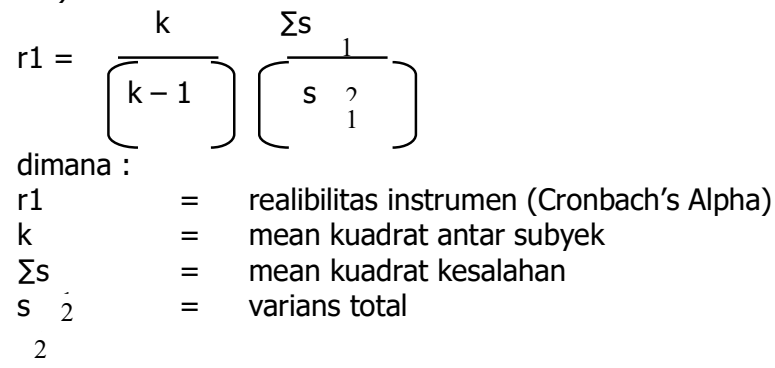

\section{Metode Analisis Data}

1. Analisis Regresi Linier Berganda

Memperkirakan faktor-faktor yang paling dominan terhadap Tidak tercapainya umur rencana jalan seperti yang direncanakan, besarnya pengaruh masing-masing variabel bebas terhadap variabel terikat ditunjukan dari besarnya nilai koefisian regresi

- $\quad$ Uji $\mathrm{F}$ adalah Untuk mengetahui apakah variabel-variabel bebas secara simultan atau keselurahan berpengaruh secara signifikan terhadap variabel terikat

$\mathrm{H}_{0}: X_{1}=X_{2}=\ldots=X_{n}=\mathbf{0}$ : menunjukan bahwa variabel faktor-faktor tidak berpengaruh terhadap tidak tercapainya umur rencana jalan hotmix.

$\mathrm{H}_{1}$ : tidak semua $X_{1} \neq X_{2} \neq X_{n} \ldots \neq \neq \mathbf{0}$ : menunjukan bahwa variabel faktor-faktor berpengaruh terhadap tidak tercapainya umur rencana jalan hotmix

- $\quad$ Uji t dilakukan untuk menguji tingkat signifikansi dari koefisien regresi secara parsial

H0: $\beta_{1}=0$; artinya bahwa variabel faktor-faktor tidak berpengaruh terhadap tidak tercapainya umur rencana jalan hotmix.

H1: $\beta_{1} \neq 0$; artinya bahwa variabel faktor-faktor mempengaruhi terhadap tidak tercapainya umur rencana jalan hotmix. 
Faktor-faktor Yang Mempengaruhi Terhadap Berkurangnya Umur Rencana Kontruksi Jalan Hotmix di Kabupaten Tulungagung. Guminto, Nusa Sebayang, Maranatha W Besarnya koefisien korelasi parsial dikatan bermakna jika $t_{\text {hitung }}>t_{\text {tabel }}$, dan ini berarti $\mathrm{H}_{0}$ ditolak dan $\mathrm{H}_{1}$ diterima.

2. Uji Klasik Asumsi Persamaan Regresi

- Asumsi Normalitas

- Asumsi Multikolinieritas

- Asumsi Heteroskedasitas

Langkah-langkah pengujian Asumsi Normalitas, Multikolinieritas, Heteroskedasistas menggunakan program bantu statistik yaitu SPSS

- Koefisien korelasi ( $r$ ) dan Koefisien Determinasi (R2)

Tabel 2 Interprestasi nilai $\mathbf{r}$

\begin{tabular}{|c|c|}
\hline Besarnya nilai $\mathbf{r}$ & Interpretasi \\
\hline Antara 0,800 sampai dengan 1,00 & Tinggi \\
\hline Antara 0,600 sampai dengan 0,800 & Cukup \\
\hline Antara 0,400 sampai dengan 0,600 & Agak rendah \\
\hline Antara 0,200 sampai dengan 0,0400 & Rendah \\
\hline Antara 0,000 sampai dengan 0,200 & Sangat rendah (tak berkorelasi) \\
\hline
\end{tabular}

Sumber: Sutrisno Hadi Prof. Metodologi Research 3 UGM Yogyakarta

\section{ANALISIS DATA}

Analisis dan pengujian dahulu validitas dan reabilitasnya ini digunakan Statistical Packaged for Sosial Sciences (SPSS).

\section{Validitas}

Pengujian validitas dilakukan dengan nilai Corrected Item-Total Correlation dengan tingkat kesalahan (nilai signifikansi) < a = 0,05 (5\%). Untuk pengujian ini digunakan Statistical Packaged for Sosial Sciences (SPSS). Hasil uji validitas untuk variabel independent, yaitu Faktor Perubahan Desain $\left(X_{1}\right)$, Faktor Kendaraan $\left(X_{2}\right)$, Faktor Lingkungan $\left(X_{3}\right)$, Faktor Sumber Daya Manusia $\left(X_{4}\right)$, Faktor Metode Pelaksanaan Pekerjaan $\left(X_{5}\right)$, Faktor Peralatan $\left(X_{6}\right)$, Faktor Kondisi Tanah $\left(X_{7}\right)$, Faktor Material $\left(X_{8}\right)$, Faktor Keuangan $\left(X_{9}\right)$. Hasil uji validitas untuk keseluruhan item pertanyaan dari variabel independent didapat dinilai Corrected Item-Total Correlation melebihi diatas 0,374 Realibilitas

Untuk menguji reabilitas digunakan metode Alpha Cronbach. Metode Alpha Cronbach digunakan untuk mencari reabilitas instrumen yang skornya bukan 1 dan 0 (ya dan tidak). Pengujian reliabilitas dilakukan dengan internal consistency atau derajat ketepatan jawaban. Untuk pengujian ini digunakan Statistical Packaged for Sosial Sciences (SPSS) dengan menggunakan koefisien Alpha Cronbach.

Instrumen dapat dikatakan andal/reliabel bila memiliki koefisien Alpha Cronbach lebih dari 0,6. apabila diperoleh nilai probabilitas $r$ hitung lebih besar dari taraf hitung signifikasi sebesar 0.05 dan memiliki koefisien reabilitas diatas 0.6 maka alat ukur yang digunakan adalah reliabel

\begin{tabular}{|l|c|c}
\multicolumn{1}{c}{ Variabel } & $\begin{array}{c}\text { Tabel } 3 \text { Uji Reliabilitas Instrumen } \\
\text { Cronbach Alpha Reliablitas }\end{array}$ & Keterangan \\
\hline Perubahan Desain & 0,681 & Reliabel \\
\hline Kendaraan & 0,791 & Reliabel \\
\hline Lingkungan & 0,686 & Reliabel \\
\hline Sumber Daya Manusia & 0,712 & Reliabel \\
\hline Metode Pelaksanaan Pekerjaan & 0,842 & Reliabel \\
\hline Peralatan & 0,715 & Reliabel \\
\hline Kondisi Tanah & 0,846 & Reliabel \\
\hline Material & 0,682 & Reliabel \\
\hline Keuangan & 0,758 & Reliabel \\
\hline
\end{tabular}

Sumber: Hasil Analisis, 2020

\section{Analisa Faktor}

Analisis faktor merupakan analisis yang digunakan untuk mengidentifikasi, mengelompokan dan meringkas indikator-indikator yang paling dominan yang berpengaruh terhadap tidak tercapainya umur rencana jalan hotmix di Kabupaten Tulungagung. Berdasarkan output analisis faktor diatas, terdapat 1 buah variabel baru yang terbentuk karena memiliki nilai total eigenvalues $\geq 1$, yaitu component 1 yang artinya faktor yang 
Faktor-faktor Yang Mempengaruhi Terhadap Berkurangnya Umur Rencana Kontruksi Jalan Hotmix

di Kabupaten Tulungagung.

Guminto, Nusa Sebayang, Maranatha W

digunakan dalam analisis faktor mampu menjelaskan variasi sebesar 66,306\%. Sehingga dapat dijelaskan bahwa component 1 merupakan yang berpengaruh terhadap tidak tercapainya umur rencana jalan hotmix

\section{Pengujian Asumsi Multikolinieritas}

Uji multikolinearitas adalah untuk menguji apakah pada model regresi ditemukan adanya korelasi antar variabel bebas (independen). Multikolinearitas berarti adanya hubungan linier yang "sempurna" atau pasti diantara beberapa atau semua variabel yang menjelaskan dari regresi

Tabel 4 Uji Multikolinearitas

Coefficients $^{a}$

\begin{tabular}{|ll|r|l|}
\hline \multirow{2}{*}{ Model } & \multicolumn{2}{|c|}{ Collinearity Statistics } \\
\cline { 3 - 4 } & & Tolerance & \multicolumn{1}{l|}{ VIF } \\
\hline 1 & Perubahan_Desain & .614 & 1.629 \\
& Kendaraan & .482 & 2.074 \\
& Lingkungan & .402 & 2.485 \\
& SDM & .333 & 2.999 \\
& Metode_Pekerjaan & .448 & 2.230 \\
& Peralatan & .455 & 2.196 \\
& Kondisi_Tanah & .390 & 2.562 \\
& Material & .281 & 3.555 \\
& Keuangan & .395 & 2.535 \\
\hline
\end{tabular}

a. Dependent Variable: Umur_Hotmix

Sumber: Hasil Añalisis, 2020

\section{Pengujian Asumsi Heterokedastisitas}

Mengetahui ada tidaknya heteroskedastisitas adalah dengan melihat grafik plot antara nilai prediksi variabel terikat yaitu ZPRED dengan residualnya SRESID. Uji ada tidaknya heteroskedastisitas dapat dilakukan dengan melihat ada tidaknya pola tertentu pada grafik scatterplot, dimana sumbu $Y$ adalah $Y$ yang telah diprediksi, dan sumbu $X$ adalah residual. Jika ada pola tertentu yang teratur, seperti titik-titik yang ada membentuk pola yang teratur (bergelombang, melebar kemudian menyempit), maka mengindikasikan telah terjadi heteroskedastisitas. Jika tidak ada pola yang jelas, serta titik-titik menyebar di atas atau di bawah angka 0 pada sumbu $Y$, maka tidak terjadi heteroskedastisitas

dapat dilihat pada grafik scatterplot berikut:

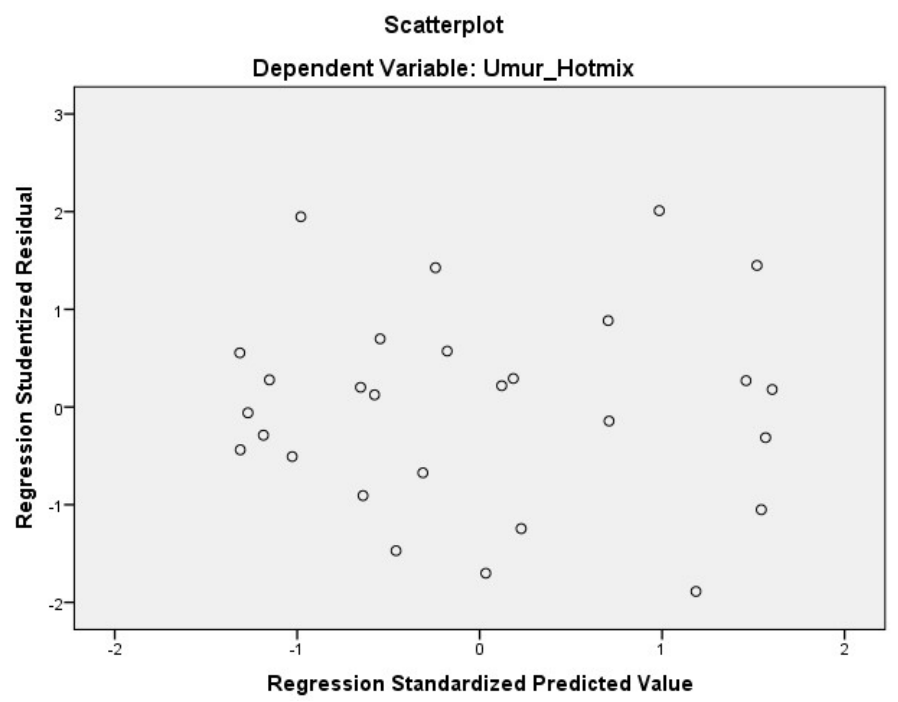

Gambar 2 Scatter Plot Uji Heteroskedastisitas

Sumber: Hasil Analisis, 2020

\section{Pengujian Asumsi Normalitas}


Faktor-faktor Yang Mempengaruhi Terhadap Berkurangnya Umur Rencana Kontruksi Jalan Hotmix di Kabupaten Tulungagung.

Guminto, Nusa Sebayang, Maranatha W

Prinsipnya normalitas dapat diuji dengan melihat penyebaran data (titik) pada sumbu diagonal dari grafik atau dengan melihat histogram dari residualnya. Jika data (titik) menyebar disekitar garis diagonal dan mengikuti arah garis diagonal atau grafik histogramnya menunjukkan pola distribusi normal, maka model regresi memenuhi asumsi normalitas

Normal P-P Plot of Regression Standardized Residual

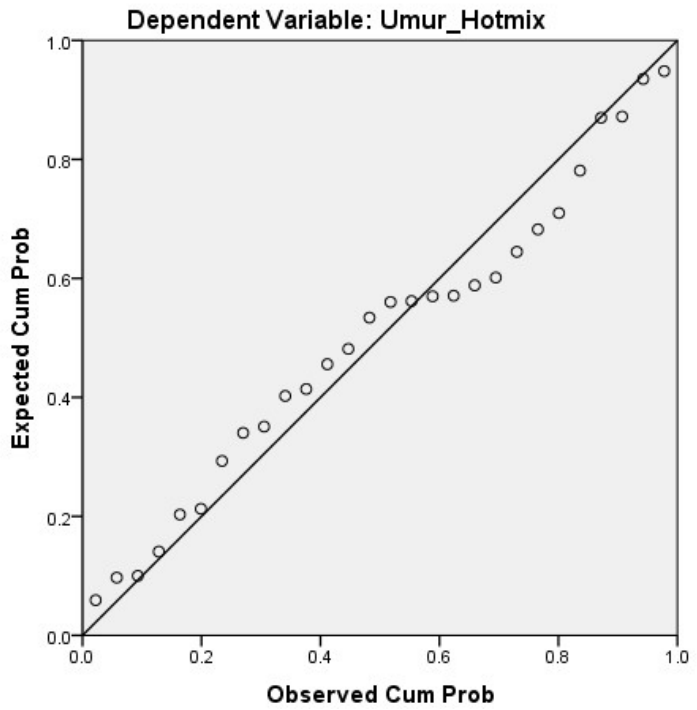

Gambar 2 Scatter Plot Uji Heteroskedastisitas

Sumber: Hasil Analisis, 2020

Analisis Regresi Linier Berganda

Untuk mengetahui apakah variabel Faktor - Faktor yanga ada secara simultan dan parsial berpengaruh signifikan terhadap tidak tercapainya umur rencana jalan Kabupaten di Kabupaten Tulungagung, Proses pengolahan data dengan menggunakan analisis regresi linier berganda, dilakukan untuk mencari hubungan antara variabel independen dan dependen. Berdasarkan hasil pengolahan data dengan menggunakan Program Bantu Statistik SPSS.

Tabel 5 Hasil Analisis Regresi Linier Berganda Coefficients $^{\mathrm{a}}$

\begin{tabular}{|c|c|c|c|c|c|c|}
\hline \multirow{2}{*}{\multicolumn{2}{|c|}{ Model }} & \multicolumn{2}{|c|}{ Unstandardized Coefficients } & \multirow{2}{*}{$\begin{array}{c}\begin{array}{c}\text { Standardized } \\
\text { Coefficients }\end{array} \\
\text { Beta }\end{array}$} & \multirow[b]{2}{*}{$\mathrm{t}$} & \multirow[b]{2}{*}{ Sig. } \\
\hline & & $\mathrm{B}$ & Std. Error & & & \\
\hline \multirow[t]{10}{*}{1} & (Constant) & 38.940 & 34.481 & & 53.702 & .000 \\
\hline & Perubahan_Desain & .865 & .148 & .122 & 1.837 & .623 \\
\hline & Kendaraan & 1.484 & .307 & .514 & 4.833 & .013 \\
\hline & Lingkungan & 1.131 & .140 & .421 & 3.994 & .037 \\
\hline & SDM & .864 & .239 & .102 & 1.613 & .987 \\
\hline & Metode_Pekerjaan & .149 & .228 & .123 & 1.042 & .485 \\
\hline & Peralatan & .187 & .119 & .241 & 1.944 & .734 \\
\hline & Kondisi_Tanah & 1.114 & .272 & .408 & 3.507 & .022 \\
\hline & Material & .968 & .126 & .237 & 1.682 & .349 \\
\hline & Keuangan & .938 & .237 & .103 & 1.966 & .079 \\
\hline
\end{tabular}

a. Dependent Variable: Umur_Hotmix

Sumber: Hasil Analisis, 2020

\section{Uji Hipotesis Koefisien Model Regresi}

Pengujian model regresi secara simultan dilakukan dengan menggunakan uji $F$ atau ANOVA dan pengujian model regresi secara parsial dilakukan dengan uji t. 
Faktor-faktor Yang Mempengaruhi Terhadap Berkurangnya Umur Rencana Kontruksi Jalan Hotmix

di Kabupaten Tulungagung.

Guminto, Nusa Sebayang, Maranatha W

Tabel 6 Uji Koefisien Determinasi

Model Summary ${ }^{\mathrm{D}}$

\begin{tabular}{|l|l|r|r|r|}
\hline Model & $\mathrm{R}$ & R Square & \multicolumn{1}{c|}{$\begin{array}{c}\text { Adjusted } \mathrm{R} \\
\text { Square }\end{array}$} & $\begin{array}{c}\text { Std. Error of } \\
\text { the Estimate }\end{array}$ \\
\hline 1 & $.898^{\mathrm{a}}$ & .895 & .993 & 1.209 \\
\hline
\end{tabular}

a. Predictors: (Constant), Keuangan, Peralatan,

Metode_Pekerjaan, Perubahan_Desain, Kendaraan,

Lingkungan, Kondisi_Tanah, SDM, Material

b. Dependent Variable: Umur_Hotmix

Sumber: Hasil Analisis, 2020

Uji Model Regresi Secara Simultan

Pengujian secara simultan dilakukan untuk menunjukkan apakah semua variabel yang digunakan dalam model regresi memiliki pengaruh yang signifikan terhadap Y. Semua variabel tersebut diuji secara serentak dengan menggunakan uji F. Dengan menggunakan perangkat lunak program bantu statistik, didapatkan hasil uji $F$ pada tabel :

Tabel 7 Uji Koefisien Determinasi

ANOVA $^{\text {a }}$

\begin{tabular}{|c|c|c|c|c|c|c|}
\hline & & $\begin{array}{l}\text { Sum of } \\
\text { Squares }\end{array}$ & df & Mean Square & $\mathrm{F}$ & Sig. \\
\hline \multirow[t]{3}{*}{$\overline{1}$} & Regression & 5431.569 & 9 & 603.508 & 43.226 & $.005^{\mathrm{b}}$ \\
\hline & Residual & 265.289 & 18 & 21.460 & & \\
\hline & Total & 5457.857 & 27 & & & \\
\hline
\end{tabular}

a. Dependent Variable: Umur_Hotmix

b. Predictors: (Constant), Keuangan, Peralatan, Metode_Pekerjaan, Perubahan_Desain, Kendaraan, Lingkungan, Kondisi_Tanah, SDM, Material

Sumber: Hasil Analisis, 2020

\section{Uji Model Regresi Secara Parsial}

Untuk menguji hubungan tersebut, digunakan uji t, yakni dengan membandingkan nilai thitung dengan $t_{\text {tabel. }}$ Variabel independen pembentuk model regresi dikatakan berpengaruh signifikan jika $t$ hitung $>t$ tabel atau signifikan $<a=0,05$, Pengujian model regresi secara parsial adalah :

Tabel 8 Hasil Uji t

\begin{tabular}{|c|c|c|c|c|c|c|}
\hline \multirow[b]{2}{*}{ Mode } & & \multicolumn{2}{|c|}{ Unstandardized Coefficients } & \multirow{2}{*}{$\begin{array}{c}\begin{array}{c}\text { Standardized } \\
\text { Coefficients }\end{array} \\
\text { Beta } \\
\end{array}$} & \multirow[b]{2}{*}{$t$} & \multirow[b]{2}{*}{ Sig. } \\
\hline & & $\mathrm{B}$ & Std. Error & & & \\
\hline \multirow[t]{10}{*}{1} & (Constant) & 38.940 & 34.481 & & 53.702 & .000 \\
\hline & Perubahan_Desain & .865 & .148 & .122 & 1.837 & .623 \\
\hline & Kendaraan & 1.484 & .307 & .514 & 4.833 & .013 \\
\hline & Lingkungan & 1.131 & .140 & .421 & 3.994 & .037 \\
\hline & SDM & .864 & .239 & 102 & 1.613 & .987 \\
\hline & Metode_Pekerjaan & .149 & .228 & .123 & 1.042 & .485 \\
\hline & Peralatan & .187 & .119 & 241 & 1.944 & .734 \\
\hline & Kondisi_Tanah & 1.114 & .272 & .408 & 3.507 & .022 \\
\hline & Material & .968 & .126 & .237 & 1.682 & .349 \\
\hline & Keuangan & .938 & .237 & .103 & 1.966 & .079 \\
\hline
\end{tabular}

a. Dependent Variable: Umur_Hotmix

Sumber: Hasil Analisis, 2020

Diperoleh nilai t hitung dari setiap variable independen dan bila t hitung dari setiap variabel independen akan dibandingkan dengan nilai t tabel dengan menggunakan tingkat kepercayaan $95 \%$ atau a $=0,05$ maka diperoleh nilai t tabel 2,056. Dengan demikian hasil uji t menjelaskan bahwa masing-masing Faktor Kendaraan $\left(X_{2}\right)$, Faktor Lingkungan $\left(X_{3}\right)$ dan Faktor Kondisi Tanah $\left(X_{7}\right)$ berpengaruh signifikan secara dominan terhadap tidak tercapainya umur rencana jalan hotmix di Kabupaten Tulungagung $(\mathrm{Y})$.

\section{KESIMPULAN DAN SARAN}

Berdasarkan hasil penelitian, analisis dan pembahasan diatas, maka penilaian-penilaian oleh para responden yang tercantum dalam kuesioner-kuesioner dalam memberikan tanggapan pada proyek pembangunan 
Guminto, Nusa Sebayang, Maranatha W

dan peningkatan jalan hotmix kabupaten di Kabupaten Tulungagung yang dapat dijadikan sebagai masukan untuk melengkapi wawasan dan informasi bagi stake holder saat merencanakan perkerasan jalan tersebut. Sehingga pada akhirnya pemerintah dalam membangun proyek tersebut, dapat memenuhi kondisi, tujuan, alasan dan manfaat secara lebih lengkap serta lebih terarah. Berikut disampaikan dari hasil penelitian, analisis dan pembahasan.

Dengan membandingkan nilai $F_{\text {hitung }}$ dengan $F_{\text {tabel, maka }} F_{\text {hitung }}(43,226)$ lebih besar dari $F_{\text {tabel }}(2,41)$. Dengan demikian Faktor Perubahan Desain $\left(X_{1}\right)$, Faktor Kendaraan $\left(X_{2}\right)$, Faktor Lingkungan $\left(X_{3}\right)$, Faktor Sumber Daya Manusia $\left(X_{4}\right)$, Faktor Metode Pelaksanaan Pekerjaan $\left(X_{5}\right)$, Faktor Peralatan $\left(X_{6}\right)$, Faktor Kondisi Tanah $\left(X_{7}\right)$, Faktor Material $\left(X_{8}\right)$, Faktor Keuangan $\left(X_{9}\right)$ secara simultan berpengaruh positif dan signifikan terhadap tidak tercapainya umur rencana jalan hotmix di Kabupaten Tulungagung $(\mathrm{Y})$.

Berdasarkan uji t secara parsial untuk mengetahui apakah masing-masing variabel independen pembentuk model regresi secara individu memiliki pengaruh yang signifikan terhadap variabel dependen atau tidak dengan membandingkan nilai $t_{\text {hitung }}$ dengan $t_{\text {tabel, }}$ didapat nilai $t_{\text {tabel }}$ dengan menggunakan tingkat kepercayaan $95 \%$ atau $a=0,05$ maka diperoleh nilai $t$ tabel 2,056. Berdasarkan hasil uji thitung berikut lebih besar dari $t$ tabel yaitu: Faktor Kendaraan $(4,833)$, Faktor Lingkungan $(3,994)$ dan Faktor Kondisi Tanah $(3,507)$ berpengaruh signifikan secara dominan terhadap tidak tercapainya umur rencana jalan hotmix di Kabupaten Tulungagung.

Berdasarkan hasil analisis, Faktor Kendaraan $\left(\mathrm{X}_{2}\right)$ adalah variabel yang memiliki koefisien beta yang paling besar (variabel yang paling dominan) yaitu 0,514 atau 51,40 persen. Artinya, variabel $Y$ (umur rencana jalan di Kabupaten Tulungangung) lebih banyak dipengaruhi oleh Variabel $X_{2}$ dibandingkan dari faktor-faktor lainnya $\left(X_{1}, X_{3}, X_{4}, X_{5}, X_{6}, X_{7}, X_{8}\right.$, dan $\left.X_{9}\right)$. Koefisien yang dimiliki oleh variabel $X_{2}$ bertanda positif, hal ini yang berarti semakin besar nilai $X_{2}$ maka semakin meningkatkan nilai variabel $Y$

\section{Kesimpulan}

1. Berdasarkan uji $F$ secara simultan didapat $F_{\text {hitung }}$ lebih besar dari $F_{\text {tabel, }}$, sehingga seluruh variabel bebas berpengaruh terhadap tidak tercapainya umur rencana jalan hotmix, sedangkan secara parsial (uji $t$ ) variabel yang berpengaruh ialah variabel kendaraan $\left(X_{2}\right)$, variabel lingkungan $\left(X_{3}\right)$ dan variabel kondisi tanah $\left(\mathrm{X}_{7}\right)$ karena nilai $\mathrm{t}$ hitung $>\mathrm{t}$ tabel.

2. Faktor yang paling dominan dalam mempengaruhi tidak tercapainya umur rencana jalan hotmix yaitu variabel kendaraan dengan nilai coofisien beta yang paling besar yaitu 0,514 atau $51,40 \%$ nilai signifikan 0,013 untuk indikatornya ialah jumlah kendaraan dengan melihat nilai looding faktor tertinggi sebesar 0,627 dan nilai keragamannya $62,70 \%$.

3. Strategi yang digunakan untuk mengatasi tidak tercapainya umur rencana jalan hotmix di Kabupaten Tulungagung dengan menyediakan jembatan timbang sesuai dengan tonase dan memberlakukan kecepatan minimal dan jam tertentu khususnya untuk kendaraan berat; Memperhitungkan dengan cermat dalam menentukan kondisi medan, dan melakukan analisis peta kontur medan; Melakukan test sandcon agar mengetahui gaya geser tanah dan daya dukung tanah yang standard nasional (AISC).

Saran

1. Dalam penelitian selanjutnya diusahakan menggunakan populasi dan sampel yang lebih banyak agar lebih baik dan dilakukan penyebaran kuisoner secara detail terhadap kualitas jalan hotmix dan membandingkan dengan beberapa daerah di Indonesia.

2. Mengklasifikasikan kelas jalan yang dijadikan sebagai basis data, sebaiknya lebih spesifik agar mendapatkan hasil yang lebih baik.

3. Untuk hasil pekerjaan yang maksimal dianjurkan menggunakan manajemen proyek dalam pelaksanaan kegiatan

\section{DAFTAR PUSTAKA}

Undang - Undang Nomor 32 Tahun 2009 tentang Lalu Lintas dan Angkutan Jalan.

Alamsyah Ansyori Alik. (2006), Rekayasa Jalan Raya, Universitas Muhammadiyah Malang.

Arikuntoro, S. (2006), Prosedur Penelitian, Edisi Revisi ke VI, Penerbit Rineka Cipta, Jakarta

Dani Widiyansah. (2017), Analisis Faktor-Faktor Yang Mempengaruhi Kerusakan Dini Pada Jalan Tipe Lentur Berdasarkan Persepsi Stakeholder (Studi Kasus: Ruas Jalan Beraspal Kabupaten Malang Jawa Timur. Universitas Muhammadiyah Surakarta

Kementerian Pekerjaan Umum dan Perumahan Rakyat Direktorat Jenderal Bina Marga. (2017). Manual Perkerasan Jalan SE: 04//SE/Db/2017, Jakarta Selatan.

Sutanto Hidayat- Maranatha W. (2019), Managemen Kontruksi dalam Perspektif Administrasi Pembangunan dan Pemasaran, Muara Karya (Anggota IKAPI), Surabaya

Aliman. (2000). Modul Ekonometrika Terapan, PAU Studi Ekonomi UGM Yogyakarta.

Puslitbang, PUPR. (2016), Laporan Kinerja Pusat Penelitian dan Pengembangan Jalan dan Jmbatan. Puslitbang Jalan dan Jembatan Bandung

Asiyanto. (2008). Metode Kontruksi Proyek Jalan Raya. Perbit, Universitas Indonesia Pres (UIP), Jakarta. 
Faktor-faktor Yang Mempengaruhi Terhadap Berkurangnya Umur Rencana Kontruksi Jalan Hotmix

di Kabupaten Tulungagung.

Guminto, Nusa Sebayang, Maranatha W

Anwar Hidayat. (2017), Interprestasi Regresi Linear dengan Eviews, https://www.statistikian.com/2017/01/interprestasi-regresi-linear-eviews.html

Cooper, R. Donald dan Emory, C William. (1999), Metode Penelitian Bisnis. Alih Bahasa : Soetjipto, W dan Wikarya, U, Penerbit Erlangga Jakarta.

Dajan, Anton. (1986), Pengantar Metode Statistik, Jilid 1 dan 2, LPES Jakarta.

Departemen Pekerjaan Umum. (1987). Petunjuk Pelaksanaan Tebal Perkerasan Jalan Raya Dengan Metode Analisa Komponen, Jakarta.

Dispohsodo, I. (1995), Managemen Proyek dan Kontruksi, Edisi Ketujuh, Penerbit Kanisius Jakarta.

Direktorat Jenderal Bina Marga Departemen Pekerjaan Umum. (1983). Standart Perencanaan Geometrik Untuk Jalan Perkotaan, Jakarta.

Draper, N, R. Dan H. Smith. (1992), Aplikasi Analisa Multivariate dengan Program SPSS, Badan Penerbit Erlangga, Jakarta.

Ghozali, I M.Com. Akt. (2006), Aplikasi Analisa Multivariate dengan Program SPSS, Badan Penerbit Universitas Diponegoro, Semarang.

Gujarati, D. (1995), Ekonometrika, Penerbit Erlangga, Jakarta.

Kezner Harold. (2005), Project Management A System Approach to Planning, Scheduling and Controling, Eight Edition, Van Nortrand Reinhold.

Maholtra, N, K. (1996), Marketing Research and Applied Orientation,Prentice Hall International, London.

Hidayat Muhammad. (2010), Faktor Faktor yang Berpengaruh Terhadap Rendahnya Kualitas Proyek Kontruksi Jalan (Studi Kasus : Pada Proyek Kontruksi Jalan Nasional di Propinsi NTB), ITN Malang.

Nugraha, P, I.Natandan R. Sucipto. (1985), Managemen Proyek Kontruksi Jilid I dan II, Penerbit Kartika Yudha Surabaya.

Riduwan. (2005), Dasar Dasar Statistik,Alfabeta, Bandung.

Santoso, Singgih. (2001), SPSS Versi 10 Mengolah Data Statistik secara Profesional, PT.Elex Media Kompitindo, Jakarta.

Soedarsono. (1999), Kontruksi Jalan Raya, Badan Penerbit Pekerjaan Umum, Jakarta Selatan.

Soeharto, I. (2008), Mangemen Proyek dari Konseptual sampai Operasional, Erlangga, Jakarta.

Sugiyono. (2009), Statistika untuk Penelitian, CV. Alfabeta. Bandung

Sukirman, Silvia. (2003), Dasar Dasar Perencanaan Geometrik Jalan Raya, Nova Bandung.

Suprapto, J. (2009), Statistik Teori dan Aplikasi Jilid 2, Penerbit Erlangga, Jakarta.

Undang - Undang Nomor 38 Tahun 2004 tentang Jalan 